POLICY BRIEFING SERIES

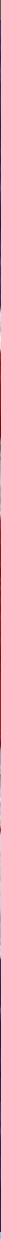

\title{
Cameron's EU reforms: political feasibility and legal implications
}

\author{
Dr. Floris de Witte
}




\section{Cameron's EU reforms: political feasibility and legal implications}

\begin{abstract}
David Cameron, the UK Prime Minister, has set out the priorities for the reform of the relationship between the UK and the EU in the run-up to an in/out referendum in 2016 or 2017. He highlights four priorities, which range from strengthening the Union's competitiveness to protecting the UK's interests in areas of market integration, migration and welfare. The extent to which these reforms will be successful depends on the legal structure of these policy areas, and the institutional veto players in the reform process.
\end{abstract}

\begin{abstract}
David Cameron, the UK's Prime Minister, has set out his objectives for EU reforms in a speech at Chatham House on 10 November 2015 - objectives which he later clarified in a letter to the President of the European Council Donald Tusk. Cameron's demands fall in four categories - i) safeguarding Britain's position in the Union's 'variable geometry'; ii) strengthening the competitiveness of the Union's internal market; iii) bolstering the democratic authority of the EU by strengthening the role of national parliaments in the EU's decision-making process; and iv) ensure changes to the principles of free movement and equal treatment of Union citizens in access to welfare systems in the host state. Each of these objectives differ quite significantly in terms of political feasibility and legal implication. More crucially, each can be interpreted and implemented in different ways. Generally, it seems, Cameron is attempting to present reforms that both address British domestic issues and strengthen the EU's functioning.
\end{abstract}

\section{The Union's variable geometry}

Cameron's concern is mainly with the relationship between Eurozone states and non-Eurozone states. He wants to "make sure that these changes [to the Eurozone] will respect the integrity of the Single Market, and the legitimate interests of non-Euro members." This is not without reason. As the EU tries to 'solve' the Euro-crisis, there has been significant deepening of integration in the Eurozone, which is moving towards oversight and coordination (and possibly, in the future, harmonisation) of national social, fiscal and welfare policies. Cameron's real problem lies in the fact that the Eurozone Member States have an in-built qualified majority in the Council. In other words, if all Eurozone states agree to a measure within the EU single market, the UK can't do anything about it. The fear is that - as integration in the Eurozone deepens to include welfare, labour, and economic policies - this will require changes to the rules, structures and institutions of the EU single market, which will also affect non-Eurozone states. Problematically, however, those states risk being structurally outvoted in the Council. Cameron sets out seven principles that serve to prevent this process. Most are easily achieved through protocols and (cosmetic) changes to the preamble of the Treaty. Cameron seems to also suggest an 'opt-out' of further market integration measures that are primarily relevant for the Eurozone states, such as the creation of a Banking Union. This should not be too difficult to secure. Short of creating a 'double majority' of both Eurozone and non-Eurozone states before an EU law can be passed (something discussed in the run-up to Cameron's speech, but which was not included), there is not much in Cameron's plan that would actually prevent the problem of Eurozone politics spilling over into the functioning of the single market. Perhaps an elegant and innovative solution can be found by the legal technicians. One example could be replacing the current legal basis for the functioning of the single market (Article 114 TFEU) with a number of more specific and detailed legal bases - be it sectoral or based on policy proximity and offering the UK an opt-out or opt-in over the ones it finds most problematic (presumably financial services and social policy considerations). This would require Treaty change and significant legal tinkering, but is not impossible to achieve, primarily because it protects both the interest of the UK and the preference of other Member States to deepen their cooperation.

\section{The Union's competitiveness}

Cameron's second heading for reform is less specific and less legally complicated. "more competitive", and highlights He stresses the need for the EU to be the need to create a single digital market, a Capital Markets Union, the cutting of red tape, and calls on the EU to "fulfil its commitment to the free flow of capital, goods and services". Notably, the fourth freedom in EU law is missing here: the free flow of citizens and workers. These demands are arguably already being met by the EU. Vice-President of the Commission Frans Timmermans has been actively trying to make sure that the EU 'does more on the big things, and less on the small things.' For instance, he is limiting the number of legislative proposals emanating from the Commission; the files for the single digital market and the Capital Markets Union are making their way through the legislative process; and the EU is negotiating a new trade and investment agreement with the US. Ultimately, however, whether or not the EU will 'deliver' on this is a question of politics: as long as the Council and EP are dominated by right-of-centre political groups, these proposals should pass relatively easily. The achievement of this second set of demands, then, might be an easy win for Cameron and does not require further protocols, negotiations or Treaty changes. Problematically for those who oppose the policy preferences of Cameron (both domestically and in Europe), this second heading for reform may be one in which other (left-of-centre) domestic leaders may be forced to compromise on. Given the difficulty of repealing or amending existing EU laws, this may make the EU even more neo-liberal than its critics argue it already is.

\section{Democratic authority in the future of the EU}

Here Cameron's intentions are clear. He wants freedom from the UK's obligation to work towards an "ever closer Union" as set out in the Treaty; to strengthen the role of national parliaments in the EU legislative process; and to bolster the functioning of the principle of subsidiarity. The first demand will not be a problem. The term 'ever closer Union' is nothing but a symbolic one and allowing the UK to opt-out by way of a protocol attached to the Treaty will not be a major political or legal issue. Cameron's second demand is relatively general. He stresses the need to involve national parliaments in EU law-making, "proposing a new arrangement where groups of national parliaments, acting together, can stop unwanted legislative proposals." This appears to alter the role of national parliaments - which now have the capacity to issue a 'yellow' or 'orange' card when they feel a Commission proposal violates the principle of subsidiarity. Cameron's letter suggests that he wishes to introduce a 
'red card', whereby national parliaments can unconditionally block policy proposals. He seems to suggest that national parliaments ought to assess the substantive merit of the proposal, rather than only its compliance with the principle of subsidiarity. In reality, research suggests that national parliaments already assess the normative and substantive merit of proposals rather than their compliance with subsidiarity. Additionally, most 'yellow' and 'orange' cards will, in practice, be 'red cards' given the unlikelihood of the Commission securing a qualified majority in the Council where national parliaments object to a proposal. In Cameron's view (which is shared by some academics), enhancing national parliaments' role in the EU serves to bolster the EU's democratic authority. However, simply strengthening the capacity of some national parliaments to say 'no' does not get us very far. It strengthens the incentives for national parliaments to protect national interest, creates negative politics and does not allow for substantive and inclusive discussion of EU politics. Moreover, it is not much used: only two proposals have been 'yellow-carded' since the introduction of this practice. An alternative way of strengthening the role of national parliaments might be to suggest that if more than half of the total number of national MPs across the 28 Member States (rather than half of national parliaments) vote against a Commission proposal, it should be abandoned. This would strengthen national oppositions (rather than playing in the hands of majorities that already control the Council in the EU), allow for the formation of cross-national political alliances, and strengthen the politicisation of EU policies along left-right cleavages, rather than national cleavages. Changes to the role of national parliaments could, to some extent, be achieved by amending Protocols 1 and 2 attached to the Treaty of Lisbon - and more structurally by writing their role into the ordinary legislative procedure by way of a Treaty revision.

\section{Welfare benefits and free movement}

The most significant and substantive proposals seek to reform inter-migration within the EU and access to welfare benefits for EU citizens in their host state. Cameron proposes that this will relieve pressure on public services and "restore a sense of fairness" to the migration structure. In practice, he proposes four specific steps. The first step is tackling 'abuse' of EU free movement law. The second step aims to prevent the fact that it's easier for an EU citizen to bring a non-EU spouse into the UK that it is for a UK national. Third, EU citizens must have lived and worked in the UK for four years before they can access in-work benefits. Fourth, child benefits should only be available for resident families, and cannot be sent back to the state of origin, where the child of a migrant worker resides. The first and fourth of these can, and probably will, be met. The need to prevent abuse of free movement law is accepted as a political priority by most Member States, and the Commission supports it as well. The case law of the European Court of Justice, moreover, allows for such measures. The nonexportability of childcare benefits is a minor, but highly symbolic issue. At the moment, child care benefits are typically accrued in the country where (one of the) parents work, even if the child resides in another country. Changing this rule of allocation, so that child benefits are exclusively paid by the country in which the child resides, regardless of the place of employment of the parents, would require amending or adding provisions in secondary EU legislation, which requires agreement between Commission, Council and EP. Given the limited nature of Cameron's request, and the consensus between dominant states about this issue, it could well be one of the compromises that can be reached (even if resistance from the EP is to be expected). The second and third demands of Cameron's list are much more difficult to achieve. Both the right for EU citizens to enter another EU state with their non-EU spouse, and the unconditional right to welfare benefits for EU citizens who work in their host state, derive from EU Treaty law directly (Articles 18, 21 and 45 TFEU). These provisions of free movement of workers and citizens, as well as the rule of non-discrimination based on nationality are central to the EU project, both symbolically, politically, and legally. Changing these rules would require unanimous support between the Member States and between all national parliaments. It is highly unlikely that all these actors are willing to rethink the conceptual and normative foundation of the Union's project in order to appease Cameron's domestic political problems. Slightly more feasible might be a re-think of the general and overall allocation of responsibility between host and home state of the migrant. Rather than forcing the host state to address the welfare needs of the migrant citizen, it may be his home state that offers the migrant welfare benefits for the first number of years. This may be a more structural way of addressing Cameron's issue without limiting the free movement provisions. However, this - again - would require unanimity between the Member States, and might not significantly reduce the burden on Britain's welfare system, given the high number of (pensionaged) Brits that reside abroad. Any other solution - such as changes to the Citizens' Directive or Social Security Regulation which implement rather general and vague Treaty provisions or any limitation of the power of the European Court of Justice - would require collaboration of Commission and EP/This is highly unlikely, and would not be "legally-binding and irreversible" given that the European Court of Justice can test the conformity of these solutions to primary EU Treaty law. In fact, part of the problem is the UK's structure of 'in-work benefits'. EU law suggests that workers have to be always treated equally when accessing welfare benefits, while access to welfare benefits for economically inactive migrants can be made conditional upon a period of residence. Yet, the UK's welfare structure does not allow Cameron to make use of this legal possibility.

\section{Conclusion}

Cameron's demands for reform of the EU in the run-up to the British in/out referendum cover a range of different issues with the EU's set-up. In general terms, Cameron can expect a lot of goodwill from the heads of state in the EU partners and the EU institutions in making certain symbolic changes (such as the opt-out of the commitment to an 'ever closer union'), and certain limited institutional and policy reforms (such as strengthening the competitiveness of the internal market or limiting the exportability of child-care benefits). More fundamental changes to the way in which the EU functions include proposed changes to the basic principles of single market policy making, free movement and equal treatment, and the role of national parliaments in the EU's legislative process. This is only achievable if negotiators can frame the reforms in such a way that addresses Cameron's needs without limiting the capacity of other institutions, states, and citizens to enjoy their rights under EU law. 


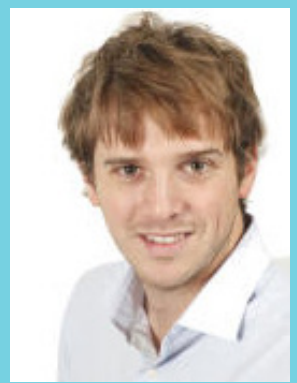

\section{DR. FLORIS DE} WITTE

Dr. Floris de Witte is Assistant Professor at the LSE. His research deals with the interaction between EU law and political theory, with particular emphasis on free movement, the Euro-crisis and the role of the individual in the EU. Floris sits on the board of editors of the German Law Journal and European Law Journal.

\section{Department of Law}

The London School of Economics

and Political Science

Houghton Street

London WC2A 2AE 